\title{
Divorce among physicians and other healthcare professionals in the United States: analysis of census survey data
}

\author{
Dan P Ly, ${ }^{1}$ Seth A Seabury, ${ }^{2}$ Anupam B Jena ${ }^{3}$
}

'Department of Medicine, Massachusetts General

Hospital, Boston, MA, USA

2Department of Emergency

Medicine and Leonard D

Schaeffer Center for Health

Policy and Economics,

University of Southern

California, Los Angeles, CA, USA

${ }^{3}$ Department of Health Care

Policy, Harvard Medical School,

Boston, MA 02115, USA;

Department of Medicine,

Massachusetts General Hospital

and National Bureau of

Economic Research, Cambridge,

MA, USA

Correspondence to: A B Jena

jena@hcp.med.harvard.edu

Cite this as: BMJ 2015;350:h706 doi: 10.1136/bmj.h706

Accepted: 6 January 2014

\author{
ABSTRACT \\ OBJECTIVES \\ To estimate the prevalence and incidence of divorce \\ among US physicians compared with other healthcare \\ professionals, lawyers, and non-healthcare \\ professionals, and to analyze factors associated with \\ divorce among physicians.

\section{DESIGN} \\ Retrospective analysis of nationally representative \\ surveys conducted by the US census, 2008-13. \\ SETTING \\ United States.
}

\section{PARTICIPANTS}

48881 physicians, 10086 dentists, 13883

pharmacists, 159044 nurses, 18920 healthcare executives, 59284 lawyers, and 6339310 other non-healthcare professionals.

\section{MAIN OUTCOME MEASURES}

Logistic models of divorce adjusted for age, sex, race, annual income, weekly hours worked, number of years since marriage, calendar year, and state of residence. Divorce outcomes included whether an individual had ever been divorced (divorce prevalence) or became divorced in the past year (divorce incidence).

\section{RESULTS}

After adjustment for covariates, the probability of being ever divorced (or divorce prevalence) among physicians evaluated at the mean value of other covariates was $24.3 \%$ ( $95 \%$ confidence interval $23.8 \%$ to $24.8 \%$ ); dentists, $25.2 \%$ (24.1\% to $26.3 \%$ ); pharmacists, $22.9 \%$ (22.0\% to $23.8 \%$ ); nurses, $33.0 \%$ (32.6\% to $33.3 \%$ ); healthcare executives, $30.9 \%$ (30.1\% to $31.8 \%$ ); lawyers, $26.9 \%$ (26.4\% to $27.4 \%$ ); and other non-healthcare professionals, $35.0 \%$ (34.9\% to $35.1 \%$ ). Similarly, physicians were less likely than those in most other occupations to divorce in the

\section{WHAT IS ALREADY KNOWN ON THIS TOPIC}

It has been speculated that the demanding nature of physicians' work leads to divorce rates that exceed those in the general population

Evidence on this both in the United States and internationally has been limited to small and dated studies and evidence has been mixed

Current, nationally representative estimates of divorce among physicians and other healthcare professionals in the United States are unknown, as are factors associated with divorce among US physicians

\section{WHAT THIS STUDY ADDS}

Despite concerns about whether the demanding nature of physicians' work leads to higher rates of divorce, divorce among physicians is less common than among the general population and several healthcare professions

Female physicians are substantially more likely to divorce than male physicians, which may be partly attributable to a differential effect of hours worked on divorce past year. In multivariable analysis among physicians, divorce prevalence was greater among women (odds ratio $1.51,95 \%$ confidence interval 1.40 to 1.63 ). In analyses stratified by physician sex, greater weekly work hours were associated with increased divorce prevalence only for female physicians.

\section{CONCLUSIONS}

Divorce among physicians is less common than among non-healthcare workers and several health professions. Female physicians have a substantially higher prevalence of divorce than male physicians, which may be partly attributable to a differential effect of hours worked on divorce.

\section{Introduction}

Professional obligations among physicians often conflict with personal and family life. ${ }^{1-5}$ While it has historically been suggested that long and sometimes unpredictable work hours among physicians may lead to higher rates of divorce, ${ }^{6-8}$ evidence on whether divorce rates among physicians exceed those in the general population has been limited and mixed..$^{8-11}$ One of the first studies to analyze this was in the United States. Published nearly 40 years ago, this study found physicians to have substantially higher rates of divorce and poor self rated marital quality than other occupations, but the study was limited in its generalizability owing to its small, non-representative sample. ${ }^{11}$ A subsequent, larger study of 1118 medical graduates of Johns Hopkins University found cumulative rates of divorce of $29 \%-$ with rates higher among psychiatrists (50\%) and surgeons (33\%)-but was limited by its analysis of physicians from a single institution..$^{9}$ Finally, a nationally representative analysis that used 1970 and 1980 US census data found similar likelihoods of divorce between physicians and other professional groups, but this study was conducted more than two decades ago. ${ }^{10}$ Although several studies done internationally have explored work-home conflicts among physicians and other healthcare professionals, ${ }^{4} 5$ 12-18 to our knowledge none have explored whether divorce among physicians is more common than in the general population.

There are many reasons to question whether previous estimates of divorce among US physicians are pertinent, given the limited sample sizes of most studies, the changes in demographics, work hours, and earnings among US physicians, ${ }^{19} 20$ and the fact that overall divorce rates in the United States have fallen dramatically since the time of these studies (from 5.2 per 1000 Americans in 1980 to 3.6 per 1000 in 2011)..$^{21}$ In this study, we revisit the question of whether physicians are more or less likely than other professionals to become divorced, by examining more than 40000 physicians and 200000 other healthcare professionals surveyed 
nationally between 2008 and 2013 in the American community survey, a large, nationally representative, annual survey of Americans conducted by the US Census Bureau. With these data we examined how the probability of divorce among physicians compared with other healthcare professionals as well as those not employed in healthcare. We analyzed factors associated with divorce among physicians, including how the number of hours worked differentially influenced the probability of divorce for male and female physicians.

\section{Methods}

\section{Data sources}

We estimated both the prevalence and the incidence of divorce in various occupational groups using the American community survey, a nationally representative, cross sectional survey of approximately three million households annually, administered by the US Census Bureau. The survey is mandatory and is collected by mail, telephone, and personal visit interviews. The survey, which includes civilian as well as military households, collects information on respondent demographics (age, sex, race, current marital status, and, since 2008, limited questions on marital history) as well as occupation, annual income, and hours worked. Response rates vary from year to year but range between $93 \%$ and $98 \% .22$

\section{Study population}

Each respondent self reported information on age, sex, race, current marital status, occupation, annual income, and weekly hours usually worked (based on hours worked at all jobs). We included individual respondents aged 25 years or more who were employed in the previous year and who reported ever being married (6649708 people from 2008 to 2013). Physicians were identified based on a self reported occupation of "physician or surgeon". Other healthcare professionals were identified based on a self reported occupation of either "dentist", "pharmacist", or "nurse". Healthcare executives were identified as those with a self reported management occupation in a healthcare industry and with a graduate degree. We also identified lawyersbased on a self reported occupation of "lawyer"-given their comparability to physicians in terms of graduate education and income. The survey does not collect data on physician specialty.

Our sample included 48881 physicians, 10086 dentists, 13883 pharmacists, 159044 nurses, 18920 healthcare executives, 59284 lawyers, and 6339610 other non-healthcare professionals.

\section{Divorce measures}

Before 2008 the American census survey only recorded current marital status (married, separated, divorced, widowed, or never married). However, since 2008, the census has asked people several additional questions related to marriage and divorce, including the year in which the respondent was married during their most recent marriage, whether or not he or she divorced in the past year, and the number of times he or she has been married. Based on these data, we characterized divorce outcomes in three ways. Firstly, we identified whether a respondent was currently divorced at the time of survey. This divorce measure provides a snapshot of whether the probability of being currently divorced at any given time varies by occupation. Secondly, because those who are currently married may have been remarried after a previous divorce, we identified whether respondents had ever been divorced, defined by whether they were either currently divorced or reported being married more than once. This divorce measure reflects the prevalence of divorce-that is, how likely someone was to have ever been divorced at any given time. Thirdly, we identified whether a respondent had divorced in the past year, which reflects the annual incidence of divorce, or what is commonly referred to as the annual divorce rate. Although in our descriptive analysis we reported unadjusted differences across occupation in each of these three measures of divorce, in our statistical analysis-which adjusted for factors associated with divorce-we used the prevalence and incidence of divorce as the primary outcomes.

\section{Statistical analysis}

We began by comparing unadjusted measures of divorce (the probability of being divorced at the time of the census survey, the probability of being ever divorced, and the probability of divorcing in the past year) among physicians, dentists, pharmacists, nurses, healthcare executives, lawyers, and others employed outside of the healthcare industry. Those who reported being currently separated from a spouse at the time of survey were not considered to be divorced.

We then estimated multivariable logistic models of divorce prevalence (whether someone had ever been divorced) and divorce incidence (whether someone divorced in the past year). Models were estimated as a function of age (categorized as 25 to 39 years, 40 to 49 years, 50 to 59 years, and $\geq 60$ years), sex, race (categorized as non-Hispanic white, non-Hispanic black, Hispanic, other), occupation, annual income (categorized as <\$50000 ( $€ 32800$; $€ 44140$ ), $\$ 50000$ to \$99999, \$100 000 to $\$ 149999, \$ 150000$ to $\$ 199999$, and $\geq \$ 200000$ ), the number of years since a respondent became married in the most recent marriage (continuous variable, defined by subtracting the year in which the respondent was married during the most recent marriage from the census survey year), and state and year fixed effects.

We adjusted for the number of years since a respondent became married in the most recent marriage for two reasons. Firstly, in comparing the prevalence of divorce across occupations, it is important to recognize that if people in specific occupations tend to marry at different ages, estimated differences in the prevalence of divorce across occupation could reflect differing ages at marriage across occupations rather than different underlying divorce risk. For example, if the annual rate of divorce was identical across occupations but physicians marry later in life, then at any given time physicians would be less likely to report ever having divorced 
compared with people in other occupations, simply because they were at risk for less time. Accounting for the length of time since someone was married is therefore important. Secondly, in comparing the incidence of divorce across occupations, it is important to note that the annual incidence of divorce (that is, the hazard rate of divorce) may vary depending on how long someone has been married. Divorce rates may be highest in the years after marriage and may decline with time, implying that the annual divorce rate for those in the 20th year of marriage would be lower than those in the first few years of marriage. ${ }^{23}$ Put differently, the divorce hazard may not be constant over time. If professionals in specific occupations marry at different ages, then a survey at a given time may misclassify occupations as having different divorce rates simply because people in those occupations were sampled at varying lengths of time after marriage. It is therefore important to adjust for the number of years since someone became married in the most recent marriage.

After estimating the logistic models, we reported the adjusted prevalence and incidence of divorce by occupation. We computed the adjusted probabilities by taking the predicted values from the logistic regression models holding all covariates except for occupation at their mean values (that is, we held the mean of other covariates constant across occupations). For categorical variables such as state and year, we computed the adjusted values at the means of the individual indicator variables (that is, reflecting the mean proportion of the sample in each category, for example, the proportion of the sample in a given state and year). In this estimation of adjusted divorce prevalence and incidence by occupation, we did not separately adjust for weekly hours worked since the difference in hours worked between physicians and non-physicians is significant and may mediate the effect of being a physician on divorce.

In addition to estimating the adjusted prevalence and incidence of divorce by occupation we examined the impact of age, race, sex, annual income, and hours worked on the prevalence and incidence of divorce among physicians, adjusting for the number of years since someone became married. Specifically, among physicians we estimated a multivariable logistic model of divorce as a function of these covariates and state and year as fixed effects. Given previous evidence that divorce rates are positively correlated with hours worked we also included weekly hours worked (categorized as $<39$ hours, 40 to 49 hours, 50 to 59 hours, and $\geq 60$ hours) in these within-occupation models. ${ }^{24}$

Finally, we stratified these models by physician sex to study whether factors such as weekly hours worked had differential impacts on the prevalence and incidence of divorce among male compared with female physicians and other healthcare professionals. This analysis was motivated by previous research in the general population of Americans, which showed that the work hours of women are more highly positively correlated with annual divorce rates than are the work hours of men. ${ }^{24}$

Sampling weights were provided by the survey and reflected the survey sampling procedures used to weight all estimates to bring the characteristics of the sample more in agreement with those of the full US population. Statistical analyses were performed using STATA version 13.1 (Stata, College Station, TX).

\section{Results}

\section{Characteristics of study population}

Table 1 lists the characteristics of the study population. The mean age of physicians was 48.6 SD 12.3) years, intermediate among other healthcare and nonhealthcare occupations. The percentage of physicians surveyed who were white was $70.2 \%$, lower than in other healthcare occupations (for example, dentists, 77.4\%; nurses, 77.0\%; healthcare executives, 79.1\%). Among healthcare occupations, physicians and dentists had the largest percentage of men $(68.3 \%$ and $75.9 \%$, respectively, compared with $8.5 \%$ among nurses and $47.7 \%$ among pharmacists). Annual income was highest among physicians (mean \$223427, SD \$155417) with $47.1 \%$ of physicians earning more than $\$ 200000$ annually. Average hours worked per week were highest among physicians (50.4 hours compared with 37.6 hours among dentists, 38.5 hours among pharmacists, 37.1 hours among nurses, 46.0 hours among healthcare executives, 45.1 hours among lawyers, and 39.8 hours in other non-healthcare occupations).

\section{Divorce among physicians versus other occupations} Divorce was less common among physicians than other occupations according to several measures (table 2). The unadjusted probability of being currently divorced at the time of survey was lowest among physicians (7.7\%, 95\% confidence interval 7.5\% to 8.0\%) compared with other occupations (dentists, $8.0 \%$; pharmacists, $8.8 \%$; nurses, $17.8 \%$; healthcare executives, $12.7 \%$; lawyers, $10.7 \%$; and other non-healthcare occupations, $17.2 \%)$. Divorce prevalence, defined as the percentage of people who reported ever being divorced at the time of survey, was lower among physicians than among most other occupations as well. Among physicians, 22.1\% (95\% confidence interval $21.8 \%$ to $22.5 \%$ ) had ever been divorced by the time of survey, compared with $22.9 \%$ among dentists, 21.5\% among pharmacists, 37.0\% among nurses, 31.3\% among healthcare executives, $27.7 \%$ among lawyers, and $36.6 \%$ among other occupations. Divorce incidence was generally lower among physicians as well. For example, 1.01\% (95\% confidence interval $0.92 \%$ to $1.10 \%$ ) of physicians divorced in the year before the survey, an annual divorce rate that was higher than that for dentists but statistically indistinguishable or lower than for all remaining occupations. Finally, physicians were less likely to have been married more than once by the time of survey compared with all other occupations except pharmacists.

Occupational differences in divorce were minimally affected by adjustment for covariates (table 3). The adjusted probability of being ever divorced-that is, divorce prevalence estimated at mean covariate values-among physicians was 24.3\% (95\% confidence interval $23.8 \%$ to $24.8 \%$ ), compared with $25.2 \%$ among dentists ( $\mathrm{P}=0.14$ for comparison with physicians), $22.9 \%$ 


\begin{tabular}{|c|c|c|c|c|c|c|c|}
\hline Characteristics & $\begin{array}{l}\text { Physicians } \\
(\mathrm{n}=48881)\end{array}$ & $\begin{array}{l}\text { Dentists } \\
(\mathrm{n}=10086)\end{array}$ & $\begin{array}{l}\text { Pharmacists } \\
(n=13 \text { 883) }\end{array}$ & $\begin{array}{l}\text { Nurses } \\
(\mathrm{n}=159 \text { 044) }\end{array}$ & $\begin{array}{l}\text { Healthcare } \\
\text { executives } \\
(\mathrm{n}=18920)\end{array}$ & $\begin{array}{l}\text { Lawyers } \\
(\mathrm{n}=59284)\end{array}$ & $\begin{array}{l}\text { Other } \\
\text { occupations } \\
(n=6339610)\end{array}$ \\
\hline \multicolumn{8}{|l|}{ Age: } \\
\hline Mean (SD) age (years) & $48.6(12.3)$ & $50.5(12.5)$ & $46.3(12.8)$ & $46.8(11.2)$ & $49.1(10.4)$ & $49.2(12.4)$ & $47.1(11.8)$ \\
\hline $25-39$ & 27.3 & 22.8 & 35.8 & 29.1 & 20.3 & 26.2 & 29.0 \\
\hline $40-49$ & 26.7 & 23.7 & 24.7 & 27.4 & 30.2 & 25.4 & 28.5 \\
\hline $50-59$ & 25.6 & 27.7 & 22.5 & 29.9 & 32.4 & 26.1 & 26.9 \\
\hline$>60$ & 20.4 & 25.8 & 17.0 & 13.7 & 17.2 & 22.4 & 15.6 \\
\hline \multicolumn{8}{|l|}{ Race: } \\
\hline White & 70.2 & 77.4 & 74.6 & 77.0 & 79.1 & 87.1 & 70.4 \\
\hline Black & 4.5 & 2.8 & 5.2 & 8.8 & 6.9 & 4.0 & 8.9 \\
\hline Hispanic & 5.7 & 5.7 & 3.4 & 4.7 & 4.5 & 4.3 & 13.7 \\
\hline Other & 19.6 & 14.1 & 16.8 & 9.5 & 9.5 & 4.6 & 7.0 \\
\hline \multicolumn{8}{|l|}{ Sex: } \\
\hline Female & 31.7 & 24.1 & 52.3 & 91.5 & 49.9 & 31.4 & 47.1 \\
\hline Male & 68.3 & 75.9 & 47.7 & 8.5 & 50.1 & 68.6 & 52.9 \\
\hline \multicolumn{8}{|l|}{ Annual income (\$): } \\
\hline Mean (SD) annual income (\$) & $223427(155417)$ & $189222(140054)$ & 109975 (61 652) & $63995(38163)$ & $143913(117284)$ & 167015 (139 497) & $53266(58104)$ \\
\hline$<50000$ & 9.5 & 10.7 & 13.1 & 34.8 & 10.6 & 13.3 & 62.0 \\
\hline 50000 to 99999 & 17.0 & 19.7 & 23.3 & 54.3 & 32.5 & 25.7 & 27.4 \\
\hline 100000 to 149999 & 13.6 & 20.7 & 51.7 & 8.8 & 26.9 & 21.8 & 6.6 \\
\hline 150000 to 199999 & 12.8 & 12.4 & 7.7 & 1.3 & 11.7 & 12.2 & 1.9 \\
\hline$>200000(\%)$ & 47.1 & 36.6 & 4.3 & 0.9 & 18.3 & 27.0 & 2.2 \\
\hline \multicolumn{8}{|l|}{ Hours worked a week: } \\
\hline Mean (SD) hours worked a week & $50.4(16.1)$ & $37.6(10.7)$ & $38.5(10.9)$ & $37.1(10.3)$ & $46.0(10.6)$ & $45.1(12.8)$ & $39.8(12.3)$ \\
\hline$<39$ & 14.6 & 46.8 & 28.4 & 44.1 & 9.0 & 15.2 & 25.6 \\
\hline 40 to 49 & 28.2 & 39.5 & 59.3 & 46.7 & 48.4 & 40.5 & 55.6 \\
\hline 50 to 59 & 22.5 & 9.4 & 8.4 & 6.1 & 28.2 & 28.2 & 11.8 \\
\hline$>60$ & 34.7 & 4.3 & 3.9 & 3.1 & 14.4 & 16.1 & 7.0 \\
\hline
\end{tabular}

$\$ 1.00$ (£0.66; €0.88).

Table 2 | Characteristics of marriage and divorce, by occupation. Values are percentages ( $95 \%$ confidence intervals) unless stated otherwise

\begin{tabular}{|c|c|c|c|c|c|c|c|}
\hline Characteristics & $\begin{array}{l}\text { Physicians } \\
(\mathrm{n}=48881)\end{array}$ & $\begin{array}{l}\text { Dentists } \\
(\mathrm{n}=10086)\end{array}$ & $\begin{array}{l}\text { Pharmacists } \\
(n=13 \text { 883) }\end{array}$ & $\begin{array}{l}\text { Nurses } \\
(\mathrm{n}=159044)\end{array}$ & $\begin{array}{l}\text { Healthcare } \\
\text { executives } \\
(\mathrm{n}=18920)\end{array}$ & $\begin{array}{l}\text { Lawyers } \\
(\mathrm{n}=59284)\end{array}$ & $\begin{array}{l}\text { Other } \\
\text { occupations } \\
(n=6339610)\end{array}$ \\
\hline \multicolumn{8}{|l|}{ Divorce: } \\
\hline Divorced at time of survey & 7.7 (7.5 to 8.0$)$ & $8.0(7.4$ to 8.5$)$ & 8.8 (8.3 to 9.2$)$ & 17.8 (17.6 to 18.0$)$ & $12.7(12.3$ to 13.2$)$ & 10.7 (10.5 to 11.0$)$ & $17.2(17.2$ to 17.2$)$ \\
\hline Pvalue & - & 0.69 & $<0.001$ & $<0.001$ & $<0.001$ & $<0.001$ & $<0.001$ \\
\hline Ever divorced & 22.1 (21.8 to 22.5$)$ & 22.9 (22.1 to 23.7$)$ & 21.5 (20.8 to 22.2$)$ & 37.0 (36.8 to 37.3$)$ & 31.3 (30.7 to 32.0$)$ & 27.7 (27.3 to 28.0$)$ & $36.6(36.5$ to 36.7$)$ \\
\hline Pvalue & - & 0.20 & 0.22 & $<0.001$ & $<0.001$ & $<0.001$ & $<0.001$ \\
\hline Divorced in past year & 1.01 (0.92 to 1.10$)$ & 0.87 (0.69 to 1.05$)$ & $1.09(0.91$ to 1.26$)$ & $1.64(1.57$ to 1.70$)$ & 1.15 (1.00 to 1.30$)$ & $1.29(1.20$ to 1.38$)$ & $1.74(1.73$ to 1.75$)$ \\
\hline Pvalue & - & 0.03 & 0.59 & $<0.001$ & 0.06 & 0.002 & $<0.001$ \\
\hline \multicolumn{8}{|l|}{ Marriage: } \\
\hline Married once & 83.8 (83.5 to 84.1) & 83.1 (82.4 to 83.9) & 85.5 (84.9 to 86.0$)$ & 75.7 (75.5 to 75.9$)$ & 78.3 (77.8 to 78.9$)$ & 80.5 (80.1 to 80.8$)$ & 75.9 (75.8 to 75.9$)$ \\
\hline Pvalue & - & 0.09 & $<0.001$ & $<0.001$ & $<0.001$ & $<0.001$ & $<0.001$ \\
\hline Married twice & 13.9 (13.5 to 14.2$)$ & 14.1 (13.4 to 14.8$)$ & 12.6 (12.0 to 13.1$)$ & 19.5 (19.3 to 19.7$)$ & 18.2 (17.6 to 18.7$)$ & 16.4 (16.1 to 16.7$)$ & 19.4 (19.4 to 19.5) \\
\hline Pvalue & - & 0.70 & 0.001 & $<0.001$ & $<0.001$ & $<0.001$ & $<0.001$ \\
\hline Married $>3$ times & $2.4(2.2$ to 2.5$)$ & 2.8 (2.5 to 3.1$)$ & 2.0 (1.7 to 2.2$)$ & 4.8 (4.7 to 4.9$)$ & 3.5 (3.2 to 3.8$)$ & $3.2(3.0$ to 3.3$)$ & $4.7(4.7$ to 4.7$)$ \\
\hline Pvalue & - & 0.002 & 0.004 & $<0.001$ & $<0.001$ & $<0.001$ & $<0.001$ \\
\hline
\end{tabular}

among pharmacists $(\mathrm{P}=0.008), 33.0 \%$ among nurses $(\mathrm{P}<0.001), 30.9 \%$ among health executives $(\mathrm{P}<0.001)$, $26.9 \%$ among lawyers $(\mathrm{P}<0.001)$, and $35.0 \%$ among other non-healthcare professionals $(\mathrm{P}<0.001)$. The adjusted probability of becoming divorced in the past year-that is, divorce incidence or divorce rate estimated at mean covariate values-among physicians was $1.0 \%$ (95\% confidence interval $0.9 \%$ to $1.1 \%$ ), compared with $1.0 \%$ among dentists $(\mathrm{P}=0.73$ for comparison with physicians), $1.0 \%$ among pharmacists $(\mathrm{P}=0.62)$, $1.3 \%$ among nurses $(\mathrm{P}<0.001), 1.1 \%$ among healthcare executives $(\mathrm{P}=0.26), 1.2 \%$ among lawyers $(\mathrm{P}=0.01)$, and $1.4 \%$ among other non-healthcare professionals $(\mathrm{P}<0.001)$.

Factors associated with divorce among physicians In adjusted analysis among physicians (table 4), both divorce prevalence and divorce incidence were more 


\begin{tabular}{|c|c|c|c|c|c|c|c|}
\hline Variables & Physicians & Dentists & Pharmacists & Nurses & $\begin{array}{l}\text { Healthcare } \\
\text { executives }\end{array}$ & Lawyers & Other occupations \\
\hline \multicolumn{8}{|l|}{ Divorce prevalence: } \\
\hline $\begin{array}{l}\text { \% of respondents ever } \\
\text { divorced, adjusted }(95 \% \mathrm{CI})\end{array}$ & 24.3 (23.8 to 24.8$)$ & $25.2(24.1$ to 26.3$)$ & 22.9 (22.0 to 23.8) & 33.0 (32.6 to 33.3) & 30.9 (30.1 to 31.8) & 26.9 (26.4 to 27.4$)$ & 35.0 (34.9 to 35.1) \\
\hline Pvalue & - & 0.14 & 0.008 & $<0.001$ & $<0.001$ & $<0.001$ & $<0.001$ \\
\hline \multicolumn{8}{|l|}{ Divorce incidence: } \\
\hline $\begin{array}{l}\% \text { of respondents divorced in } \\
\text { past year, adjusted }(95 \% \mathrm{Cl})\end{array}$ & 1.0 (0.9 to 1.1) & $1.0(0.7$ to 1.2$)$ & 1.0 (0.8 to 1.2$)$ & $1.3(1.2$ to 1.4$)$ & 1.1 (1.0 to 1.3$)$ & $1.2(1.1$ to 1.4$)$ & $1.4(1.4$ to 1.4$)$ \\
\hline$P$ value & - & 0.73 & 0.62 & $<0.001$ & 0.26 & 0.01 & $<0.001$ \\
\hline
\end{tabular}

Pvalues are based on comparison with physicians.

Adjusted prevalence and incidence of divorce across occuptions were estimated from multivariable logistic model of divorce as a function of occupational category, age, sex, race, annual income, years since became married in most recent marriage, and state and year fixed effects. The predicted values were calculated holding all covariates at their mean values.

\begin{tabular}{|c|c|c|}
\hline & Adjusted odds rati & \\
\hline Characteristics & Ever divorced & Divorced in past year \\
\hline \multicolumn{3}{|l|}{ Age (years): } \\
\hline $25-39$ & 1 (reference) & 1 (reference) \\
\hline $40-50$ & 5.79 (5.16 to 6.49$)$ & $1.87(1.35$ to 2.59$)$ \\
\hline $51-60$ & 28.0 (24.6 to 31.9) & 1.84 (1.25 to 2.70$)$ \\
\hline$>60$ & 133 (112 to 158$)$ & 1.91 (1.17 to 3.11) \\
\hline \multicolumn{3}{|l|}{ Race: } \\
\hline White & 1 (reference) & 1 (reference) \\
\hline Black & 1.09 (0.92 to 1.28$)$ & 0.61 (0.32 to 1.17$)$ \\
\hline Hispanic & 1.13 (0.99 to 1.30$)$ & 1.09 (0.67 to 1.78$)$ \\
\hline Other & $0.43(0.39$ to 0.47$)$ & 0.56 (0.40 to 0.78$)$ \\
\hline \multicolumn{3}{|l|}{ Sex: } \\
\hline Male & 1 (reference) & 1 (reference) \\
\hline Female & 1.51 (1.40 to 1.63$)$ & 1.46 (1.14 to 1.88$)$ \\
\hline \multicolumn{3}{|l|}{ Annual income (\$): } \\
\hline$<50000$ & 1 (reference) & 1 (reference) \\
\hline 50000 to 99999 & 1.00 (0.87 to 1.16$)$ & 0.93 (0.59 to 1.48$)$ \\
\hline 100000 to 149999 & $1.07(0.93$ to 1.24$)$ & 1.24 (0.79 to 1.96$)$ \\
\hline 150000 to 199999 & $1.06(0.92$ to 1.23$)$ & 1.02 (0.63 to 1.63$)$ \\
\hline$>200000$ & 1.03 (0.90 to 1.17$)$ & 0.94 (0.60 to 1.46$)$ \\
\hline \multicolumn{3}{|l|}{ Hours worked a week: } \\
\hline$<39$ & 1 (reference) & 1 (reference) \\
\hline 40 to 49 & 1.02 (0.93 to 1.12 ) & 1.41 (0.98 to 2.02$)$ \\
\hline 50 to 59 & 0.86 (0.78 to 0.95$)$ & $1.36(0.90$ to 2.04$)$ \\
\hline$>60$ & 0.79 (0.72 to 0.87$)$ & $1.10(0.76$ to 1.61$)$ \\
\hline
\end{tabular}

$\$ 1.00$ (£0.66; €0.88)

Table reports adjusted odds ratios from multivariable logistic model of divorce (prevalence or incidence) as function of age, race, sex, annual income, hours worked a week, years since became married in most recent marriage, and state and year fixed effects. Predicted values were calculated holding all covariates at their mean values. Divorce prevalence is percentage of individuals who reported having ever been divorced at time of survey. Annual divorce incidence is the percentage of individuals who divorced in year previous to survey and can be interpreted as annual divorce rate. than 39 hours was $0.79,95 \%$ confidence interval 0.72 to 0.87). However, no association was noted between hours worked and the adjusted probability of divorcing in the past year. Confidence intervals around odds ratios in the model of divorce in the past year were generally larger than in the model of being ever divorced, owing to the much lower frequency of events in the former group.

\section{Sex differences in effect of hours worked by physicians on divorce}

The number of hours worked per week was positively associated with the probability of being ever divorced only among female physicians (table 5). Female physicians who worked more than 40 hours a week had a higher probability of being ever divorced compared with female physicians who worked less than 40 hours a week (for example, adjusted odds ratio 1.34 for female physicians working 40-49 hours a week compared with $<40$ hours, 95\% confidence interval 1.16 to 1.54 ; adjusted odds ratio 1.16 for female physicians working 50 to 59 hours a week compared with $<40$ hours, 95\% confidence interval 0.99 to 1.37). In contrast, male physicians who worked more than 40 hours a week had lower odds of being ever divorced than male physicians who worked less than 40 hours a week (adjusted odds ratio 0.77 for male physicians working $40-49$ hours a week (95\% confidence interval 0.68 to 0.88 ) and 0.66 (0.58 to 0.75 ) for male physicians working 50-59 hours a week, both compared with male physicians working $<40$ hours a week).

\section{Discussion}

The demanding nature of physicians' work has led to several historical investigations in the United States of whether divorce is more common among physicians than among other professionals. However, evidence on this has been dated, limited, and mixed. ${ }^{8-11}$ Using large, nationally representative survey data collected by the US census from 2008 to 2013, we compared both the prevalence and incidence of divorce among physicians and other healthcare and non-healthcare professionals.

Our study had several findings. Firstly, divorce among US physicians is no more common than in other healthcare professions and non-healthcare professions. In fact, the prevalence and incidence of divorce among physicians were similar to pharmacists and 


\begin{tabular}{|c|c|c|}
\hline \multirow{2}{*}{$\begin{array}{l}\text { Hours worked } \\
\text { a week }\end{array}$} & \multicolumn{2}{|c|}{ Adjusted odds ratio of ever divorce $(95 \% \mathrm{Cl})$} \\
\hline & Men & Women \\
\hline$<39$ & 1 (reference) & 1 (reference) \\
\hline 40 to 49 & $0.77(0.68$ to 0.88$)$ & $1.34(1.16$ to 1.54$)$ \\
\hline 50 to 59 & 0.66 (0.58 to 0.75$)$ & 1.16 (0.99 to 1.37$)$ \\
\hline$>60$ & $0.59(0.52$ to 0.67$)$ & 1.10 (0.93 to 1.28$)$ \\
\hline \multicolumn{3}{|c|}{$\begin{array}{l}\text { Table reports adjusted odds of physician divorce (prevalence and } \\
\text { incidence) as function of hours worked a week. Results are from } \\
\text { multivariable logistic model, which also adjusted for age, race, annual } \\
\text { income, years since became married in most recent marriage, and state } \\
\text { and year fixed effects. Separate models were estimated by physician sex. } \\
\text { Predicted values were calculated holding all covariates at their mean } \\
\text { values in each estimation sample. Divorce outcome is percentage of } \\
\text { individuals who reported having ever been divorced at time of survey. }\end{array}$} \\
\hline
\end{tabular}

dentists and substantially lower than that of nurses, healthcare executives, lawyers, and other nonhealthcare professionals. Despite evidence that professional obligations among physicians, including long and sometimes unpredictable work hours, may conflict with personal and family life, ${ }^{1-3}$ we found no evidence that divorce among physicians was more common as a result. Secondly, female physicians were substantially more likely to be divorced than male physicians. Hours worked per week were positively correlated with divorce only for female physicians and not for male physicians, suggesting that differences in divorce rates between male and female physicians may be partly attributable to differential responses of divorce to hours worked.

\section{Meaning of the study and relation to other studies of US healthcare professionals}

Our findings of a lower prevalence and incidence of divorce among physicians compared with lawyers and other professionals not employed in healthcare mirror findings from analyses of 1970 and 1980 US census data reported more than two decades previously. ${ }^{10}$ In that analysis, physicians were compared with lawyers with similar sociodemographic characteristics, including advanced education, comparatively high income, and later age at marriage. That analysis did not, however, compare divorce between physicians and other healthcare professionals who may face similar professional demands. In that respect we found physicians to be similarly likely to divorce as dentists and pharmacists but to have a lower prevalence of divorce than nurses and healthcare executives.

An important measure that we could not assess is the subjective evaluation of marital quality, which is distinct from proneness to divorce, which we assessed. ${ }^{102526} \mathrm{Sev}$ eral survey studies in the United States have evaluated marital quality among physicians and have examined factors associated with self reported marital quality, including hours worked, physician specialty area, practice setting, spousal occupation, and presence of children. ${ }^{26-29}$ For example, in a US survey of 891 spouses of physicians, satisfaction was strongly independently associated with time spent awake with their physician partner and number of nights on call a week but was not associated with other professional characteristics such as total hours worked a week, specialty area, or practice setting..$^{29}$
Our finding that female physicians are substantially more likely than male physicians to report being divorced raises important questions as to the origin of this association. In US surveys, female physicians on average report making greater professional adjustments than male physicians to accommodate for household responsibilities such as child rearing. ${ }^{30}$ Greater trade-offs between professional obligations and family life may contribute to lower quality of relationships and higher prevalence of divorce among female physicians. ${ }^{31} 32$ For example, in a US survey of 1043 female and 6815 male surgeons, female surgeons were substantially more likely to report having experienced a conflict with their spouse or partner's career $(52.6 \% \mathrm{v}$ $41.2 \%$ ), more likely to report experiencing a work-home conflict in the three weeks preceding the survey being administered (62.2\% $v 48.5 \%$ ), and more likely to report symptoms of burnout and depression. ${ }^{2}$

Our analysis also found a positive association between hours worked per week and divorce for female physicians. In contrast, hours worked per week were negatively associated with divorce for male physicians. This finding is consistent with previous evidence from the general American population that work hours of women are more highly positively correlated with divorce than are work hours of men. ${ }^{24}$ Our finding that hours worked a week may have different impacts on divorce for female versus male physicians is consistent with evidence that female physicians report making greater trade-offs between professional and family obligations. ${ }^{30-32}$ Although we studied the impact of number of hours worked on divorce, our analysis did not allow us to study the association of divorce with the structure of hours worked-for example, irregular shifts or nighttime work-which in a previous study was associated with self reported marital dissatisfaction among spouses of physicians. ${ }^{29}$

\section{Relation to international studies}

We were unable to identify published studies exploring divorce among physicians and other healthcare professionals outside of the United States. However, several studies conducted internationally have explored rates of physician burnout and factors associated with wellbeing, and specifically explored sex differences in workhome conflict. ${ }^{4512-18}$ For example, in a survey of 1208 Norwegian physicians, work-home conflict was among the strongest predictors of burnout among female physicians but was not statistically significant among male physicians. ${ }^{4}$ Similarly, in an analysis of multiple cohorts of newly qualified physicians in the United Kingdom between 1974 and 1993, 11.7\% of male doctors were married compared with $21.5 \%$ of men in the general population, whereas only $14.1 \%$ of women doctors were married compared with $38.9 \%$ of women in the general population..$^{13}$ This study, while informative about sex differences in marriage formation among UK physicians, did not analyze rates of divorce. Finally, in a comparative analysis of sex differences in burnout among physicians in the United States compared with the Netherlands, US female physicians experienced more 
burnout than US male physicians, whereas there was no sex difference in burnout among Dutch physicians. However, consistent with other studies, female physicians in both the United States and the Netherlands reported more work-home conflicts than did men, with the size of the sex difference twice as high in the United States as in the Netherlands. ${ }^{5}$

\section{Strengths and weaknesses of this study}

This study is the first in the past three decades to estimate the prevalence and incidence of divorce among US physicians using large, nationally representative data; to compare those estimates with other healthcare professionals, lawyers, and other non-healthcare professionals; and to analyze factors associated with divorce among physicians.

Our study has several limitations. Firstly, although the analysis of divorce rates across occupations lends itself to a hazard analysis (for example, Cox proportional hazards analysis of differences in divorce hazards across occupations), the census does not follow people longitudinally as it is a cross sectional survey of people. Future work should use hazard analysis to compare divorce rates of physicians with non-physicians in longitudinal data, which would allow for direct estimation of the differences across occupations in adjusted probability of divorce for people over time.

A second limitation is that divorce is an imperfect measure of marital satisfaction, the latter which we were unable to directly assess in our study. A comparison of marital satisfaction between physicians and other professionals may reveal differences that a comparison of divorce may not. Thirdly, the American community survey did not contain information on physician specialty. Although a failure to account for physician specialty would not affect our comparison of divorce between physicians and other professionals, there may be important differences in divorce among specialties. For example, in a previous study of medical school graduates from Johns Hopkins University, specialties such as psychiatry and surgery were found to have substantially higher rates of divorce than internal medicine, pediatrics, and pathology. ${ }^{9}$ Fourthly, our data did not allow us to estimate the prevalence of divorce among dual-physician couples. Dual-physician couples have increased in prevalence, with several estimates suggesting that nearly half of all physicians are married to other physicians. ${ }^{30} 334$ Dual-physician couples may also be more common among female physicians than among male physicians. ${ }^{235}$ Marital satisfaction and divorce may differ between physicians who are married to other physicians and those who are not. For example, in a study of 7095 surgeons, surgeons in dual-physician couples reported greater difficulty balancing professional and personal obligations compared with surgeons whose spouse was not a physician. ${ }^{33}$ In contrast, in a study of 1208 physicians, those in dual-physician couples reported an equivalent likelihood to nonphysician couples of achieving both career and family goals. ${ }^{30}$ Both groups also reported equivalent levels of conflict between professional obligations and family roles. Although our data allowed us to identify spousal occupation, we could not analyze the prevalence of divorce among dual-physician couples because divorced people in the survey had no occupational data recorded for the previous spouse. Finally, our data were specific to the United States and may not generalize to divorce among healthcare professionals internationally, although some evidence exists that rates of burnout, which likely correlate with rates of divorce, may be similar between healthcare professionals in the United States and United Kingdom. ${ }^{15} 36$

\section{Conclusion}

Despite often reported conflicts between professional obligations and family life, we found no evidence that physicians in the United States have a higher prevalence or incidence of divorce than other healthcare and non-healthcare professionals. Female physicians and other female healthcare professionals are substantially more likely to be divorced than their male counterparts, an area that requires further investigation.

Contributors: DPL, SAD, and ABJ contributed to the design and conduct of the study, data collection and management, interpretation of the data; and preparation, review, or approval of the manuscript. $A B J$ is guarantor. The study sponsors were not involved in the study design, data interpretation, writing, or decision to submit the article for publication.

Funding: This study was supported by the Office of the Director, National Institutes of Health.

Competing interests: All authors have completed the ICMIE uniform disclosure form at www.icmje.org/coi_disclosure.pdf (available on request from the corresponding author) and declare: $A B$ J had support from the Office of the Director, National Institutes of Health (NIH early independence award, grant 1DP50D017897-01) for the submitted work; no financial relationships with any organisations that might have an interest in the submitted work in the previous three years; and no other relationships or activities that could appear to have influenced the submitted work.

Data sharing: No additional data available.

Ethical approval: Not required.

Transparency: The lead author (ABJ) affirms that the manuscript is an honest, accurate, and transparent account of the study being reported; that no important aspects of the study have been omitted; and that any discrepancies from the study as planned (and, if relevant, registered) have been explained.

This is an Open Access article distributed in accordance with the Creative Commons Attribution Non Commercial (CC BY-NC 4.0) license, which permits others to distribute, remix, adapt, build upon this work non-commercially, and license their derivative works on different terms, provided the original work is properly cited and the use is noncommercial. See: http://creativecommons.org/licenses/by-nc/4.0/.

1 Shanafelt TD, Balch CM, Bechamps GJ, Russell T, Dyrbye L, Satele D, et al. Burnout and career satisfaction among American surgeons. Ann Surg 2009;250:463-71.

2 Dyrbye LN, Shanafelt TD, Balch CM, Satele D, Sloan J, Freischlag J. Relationship between work-home conflicts and burnout among American surgeons: a comparison by sex. Arch Surgy 2011;146:211-7. 3 Dyrbye LN, West CP, Satele D, Sloan JA, Shanafelt TD. Work/Home conflict and burnout among academic internal medicine physicians. Arch Intern Med 2011;171:1207-9.

4 Langballe EM, Innstrand ST, Aasland OG, Falkum E. The predictive value of individual factors, work-related factors, and work-home interaction on burnout in female and male physicians: a longitudinal study. Stress Health 2011;27:73-87.

5 Linzer M, McMurray JE, Visser MR, Oort FJ, Smets E, de Haes HC. Sex differences in physician burnout in the United States and The Netherlands. J Am Med Womens Assoc 2002;57:191-3.

6 Myers MF. The well-being of physician relationships. West) Med 2001;174:30-3.

Derdeyn AP. The physician's work and marriage. Int J Psychiatry Med 1978;9:297-306. 
8 Rose KD, Rosow I. Marital stability among physicians. CalifMed 1972;116:95-9.

9 Rollman BL, Mead LA, Wang NY, Klag MJ. Medical specialty and the incidence of divorce. N Engl J Med 1997;336:800-3.

10 Doherty WJ, Burge SK. Divorce among physicians. Comparisons with other occupational groups. JAMA 1989:261:2374-7.

11 Vaillant GE, Sobowale NC, McArthur C. Some psychologic vulnerabilities of physicians. N Engl / Med 1972;287:372-5

12 Innstrand ST, Langballe EM, Falkum E, Aasland OG. Exploring within- and between-gender differences in burnout: 8 different occupational groups. Int Arch Occup Environ Health 2011;84:813-24

13 Lambert TW, Goldacre MJ, Parkhouse J. Doctors who qualified in the UK between 1974 and 1993: age, gender, nationality, marital status and family formation. Med Educ 1998;32:533-7.

14 Calnan M, Wainwright D, Forsythe M, Wall B, Almond S. Mental health and stress in the workplace: the case of general practice in the UK. Soc Sci Med 2001:52:499-507.

15 Soler JK, Yaman H, Esteva M, Dobbs F, Asenova RS, Katic M, et al. Burnout in European family doctors: the EGPRN study. Fam Pract 2008;25:245-65.

16 Panagopoulou E, Montgomery A, Benos A. Burnout in interna medicine physicians: differences between residents and specialists. Eur J Intern Med 2006;17:195-200.

17 Orton P, Orton C, Pereira Gray D. Depersonalised doctors: a cross-sectional study of 564 doctors, 760 consultations and 1876 patient reports in UK general practice. BMJ Open 2012;2:e000274.

18 Ro KE Gude T, Tyssen R, Aasland OG. Counselling for burnout in Norwegian doctors: one year cohort study. BMJ 2008;337:a2004.

19 Seabury SA, Jena AB, Chandra A. Trends in the earnings of health care professionals in the United States, 1987-2010. JAMA 2012;308:2083-5.

20 Seabury SA, Chandra A, Jena AB. Trends in the earnings of male and female health care professionals in the United States, 1987 to 2010. JAMA Intern Med 2013;173:1748-50.

21 Centers for Disease Control and Prevention. National marriage and divorce rate trends, 2014

22 US Census Bureau. Fact sheet-differences between CPS ASEC and ACS, 2014
23 Bureau USC. Number, timing, and duration of marriages and divorces: 2001, 2005.

24 Johnson J. Do long work hours contribute to divorce? Top Econ Anal Policy 2004; 4

25 Spanier GB. The measurement of marital quality. I Sex Marital Ther 1979;5:288-300.

26 Gabbard GO, Menninger RW, Coyne L. Sources of conflict in the medical marriage. Am J Psychiatry 1987;144:567-72.

27 Barnett RC, Gareis KC, Carr PL. Career satisfaction and retention of a sample of women physicians who work reduced hours. J Womens Health 2005; 14:146-53.

28 Warde CM, Moonesinghe K, Allen W, Gelberg L. Marital and parental satisfaction of married physicians with children. J Gen Intern Med 1999:14:157-65.

29 Shanafelt TD, Boone SL, Dyrbye LN, Oreskovich MR, Tan L, West CP, et al. The medical marriage: a national survey of the spouses/partners of US physicians. Mayo Clin Proc 2013:88:216-25.

30 Sobecks NW, Justice AC, Hinze S, Chirayath HT, Lasek RJ, Chren MM, et al. When doctors marry doctors: a survey exploring the professional and family lives of young physicians. Ann Intern Med 1999:130(4 Pt 1):312-9.

31 Myers MF. Overview: the female physician and her marriage. Am J Psychiatry 1984;141:1386-91.

32 Myers MF. Doctors and divorce. When medicine, marriage, and motherhood don't mix. Med Econ 1998;75:100-2, 05, 09-10.

33 Dyrbye LN, Shanafelt TD, Balch CM, Satele D, Freischlag J. Physicians married or partnered to physicians: a comparative study in the American College of Surgeons. J Am Coll Surg 2010;211:663-71.

34 Relman AS. The changing demography of the medical profession. N Engl J Med 1989;321:1540-2

35 Schroen AT, Brownstein MR, Sheldon GF. Women in academic general surgery. Acad Med 2004;79:310-8.

36 Ramirez AJ, Graham J, Richards MA, Cull A, Gregory WM, Leaning MS, et al. Burnout and psychiatric disorder among cancer clinicians. Br J Cancer 1995;71:1263-9. 